J. comp. Physiol. 81, 289-299 (1972)

(C) by Springer-Verlag 1972

\title{
Aerobic and Anaerobic Metabolism during Activity in the Lizard Dipsosaurus dorsalis
}

\author{
Albert F. Bennett \\ Department of Zoology, University of California, Berkeley, California \\ William R. Dawson \\ Department of Zoology, The University of Michigan, Ann Arbor, Michigan
}

Received September 25, 1972

Summary. 1. Oxygen consumption and lactate content of the lizard Dipsosaurus dorsalis were determined under standard conditions and for a bout of maximal activity induced by a 2 -min period of electrical stimulation. Observations were made between $25^{\circ}$ and $45^{\circ} \mathrm{C}$.

2. Maximal aerobic scope, $2.27 \mathrm{~cm}^{3} \mathrm{O}_{2} /\left(\mathrm{g} \times \mathrm{hr}\right.$ ), occurred at $40^{\circ} \mathrm{C}$ (Figs. 2, 4). The increase in oxygen consumption during activity at the various temperatures between $25^{\circ}$ and $45^{\circ} \mathrm{C}$ represented 7 - to 17 -fold of corresponding resting levels.

3. Lactate content of resting Dipsosaurus is independent of temperature and averages $0.25 \mathrm{mg} / \mathrm{g}$ body weight. Maximal lactate production during the activity induced by a 2-min period of electrical stimulation occurred at $40^{\circ} \mathrm{C}$ (Fig. 3). The capacity of Dipsosaurus for anaerobic metabolism exceeds that of other lizards investigated, both in its magnitude and in its thermal dependence.

4. The total amount of energy mobilized by Dipsosaurus in the activity induced by a 2-min period of electrical stimulation was maximal at $40^{\circ} \mathrm{C}$ (Fig. 4). Anaerobiosis accounts for a minimum of $58-83 \%$ of the total energetic expenditure.

5. It is postulated that the principal physiological adaptations to preferred thermal levels in reptiles have involved energy mobilization during and rapid recovery after activity.

\section{Introduction}

Considerable information has been collected on the physiology and ecology of Dipsosaurus dorsalis, the desert crested iguana (see, for example, Cook, 1949; Norris, 1953; Dawson and Bartholomew, 1958; Dawson and Poulson, 1962; DeWitt, 1963, 1967a, b; Moberly, 1963 ; Licht, 1965; Mayhew, 1965a, 1968, 1971; Weathers, 1970; Minnich, $1970 \mathrm{a}, \mathrm{b}$; Minnich and Shoemaker, 1970; Beckman et al., 1971). This lizard is a relatively common herbivore in deserts in parts of California, Arizona, Nevada, Utah, and northern Mexico, and is notable for its high activity temperatures and thermal tolerance. Preferred body temperature is $38.5^{\circ} \mathrm{C}$ in laboratory thermal gradients, but animals normally are warmer than this while active in nature (DeWitt, 1966, 1967a). Norris (1953) reported a mean field temperature of $42.1^{\circ} \mathrm{C}$ and Mayhew 
(1968) found that $75 \%$ of the Dipsosaurus sampled in their natural habitat had body temperatures of $40^{\circ} \mathrm{C}$ or higher. Body temperatures as high as $47^{\circ} \mathrm{C}$ have been observed in this species under field conditions (Mayhew, 1968), the highest value reported for any reptile and among the highest for all vertebrates.

Dipsosaurus are active animals, capable of rapid movement even during the hottest part of the day. Belkin (1961) found their running speed to average $7.3 \mathrm{~m} / \mathrm{sec}(16.3 \mathrm{mph})$, with a maximum value of $8.5 \mathrm{~m} / \mathrm{sec}(19.0 \mathrm{mph})$. High temperatures are known to decrease the oxygen affinity and oxygen capacity of the blood of desert lizards (Dill et al., 1935; Dill, 1938; Bennett, 1971), creating difficulties in oxygen procurement. The problems of oxygen transport would be particularly great during activity, when demand is greatest. Oxygen capacity in Dipsosaurus $(9.5 \mathrm{rol} . \%)$ is identical to the mean for iguanid lizards (Dawson and Poulson, 1962). This species has a slightly greater oxygen affinity $\left(\mathrm{P}_{50}=66 \mathrm{~mm} \mathrm{Hg}\right.$ at $\left.40^{\circ} \mathrm{C}\right)$ than other lizards examined (Pough, 1969), but the effects of temperature on oxygen capacity have not been determined. Myoglobin levels are low in Dipsosaurus, averaging $0.3 \mathrm{mg} / \mathrm{g}$ muscle (Bennett, unpublished data).

In contrast to the undistinguished abilities of Dipsosaurus for oxygen procurement and transport, a variety of physiological observations suggest that this lizard might have pronounced capacities for sustained anaerobic activity. It produces higher levels of lactate per g of body weight during prolonged exertion than lizards of other species examined, and does not exhaust so readily (Bennett and Licht, 1972). This iguanid also has high levels of lactate dehydrogenase activity in blood plasma (H. Pough, personal communication), skeletal muscle, and liver (Bennett, 1972a). The protein-specific activity of phosphofructokinase, the enzyme catalyzing the rate-limiting step in glycolysis, in the skeletal muscle of Dipsosaurus is five times that in laboratory rats and twice that in another desert iguanid, Sauromalus hispidus (Bennett, 1972a).

The foregoing considerations prompted our interest in determining the relative roles of aerobic and anaerobic energy liberation in activity of Dipsosaurus. Neither of these factors has been determined previously because of the technological difficulties which they present. A new technique for the determination of total lactate production during activity has recently been developed (Bennett and Licht, 1972). Aerobic scope, the increment in oxygen consumption during maximal activity (Fry, 1947), is too small in animals the size of Dipsosaurus to permit determination by open-flow oxygen analysis. We have utilized a closed circuit technique, modified from one developed by R. Gatten (personal communication), through which low levels of oxygen consumption can be determined with a paramagnetic oxygen analyzer. We believe this 
to be the first study in which the aerobic and anaerobic contributions to total energetic expenditure during activity have been measured simultaneously in reptiles.

\section{Material and Methods}

Adult Dipsosaurus dorsalis were collected in late April, 1972, near Palm Springs, Riverside Co., California (California Scientific Collector's Permit No. 643 to AFB) and transported by air to The University of Michigan, where all experimental procedures were performed in May, 1972. The animals were maintained in wooden and screen cages and given access to incandescent lamps set on a $7 \cdot \mathrm{hr}$ photoperiod. Their diet consisted of Tenebrio larvae, lettuce, and dandilion (Taraxacum officinale) blossoms. Water was available at all times. The animals remained in excellent physical condition. Each was fasted at least two days before study.

Standard metabolic rates were determined on 30 individual Dipsosaurus (mean weight, $35.2 \mathrm{~g}$; range, $28.7-42.6 \mathrm{~g}$ ). The animals were weighed and fitted with electrodes, which were attached near the base of the tail musculature. The leads from these electrodes were fastened to the tail with masking tape. Free movement of the limbs and body was not hampered by the electrodes or leads. The animals were placed in black, light-tight chambers with an inner diameter of $7.8 \mathrm{~cm}$ and a volume of 1.8 or 2.6 liters. These chambers were fashioned from lengths of polyvinyl chloride drain pipe. The ends of the pipe were sealed with rubber stoppers containing ports for electrical leads and air lines. The chamber also contained a deflated latex condom (Youngs Drug Products Corp., Piscataway, New Jersey) for pressure compensation during air sampling after activity. The latter was connected to the outside via one of the air ports. The chambers were placed in a temperature cabinet at $25^{\circ}, 30^{\circ}, 35^{\circ}, 40^{\circ}$ or $45^{\circ} \mathrm{C}$ before 1200 EST. Air was metered through them at $100-350 \mathrm{~cm}^{3} / \mathrm{min}$. Standard rates of oxygen consumption by the lizards in these chambers were measured for at least an hour after 2000 EST by passing dry, $\mathrm{CO}_{2}$-free air from the excurrent air lines through a Beckman paramagnetic oxygen analyzer (model $\mathrm{G} * 2$; range $20-21 \% \mathrm{O}_{2}$ ) connected to a Honeywell Class 15 recorder. These lines each contained an absorbent train of Drierite (anhydrous $\mathrm{CaSO}_{4}$ ) and Ascarite (Na-hydrate asbestos) for the absorption of water vapor and $\mathrm{CO}_{2}$, respectively. The method of Hill (1972) was used for calculation of these rates. A second Honeywell Class 15 recorder was used in conjunction with copper-constantan thermocouples for monitoring chamber temperatures.

After determination of standard metabolism, the lizards' total oxygen consumption and lactate production were measured after a bout of maximal activity induced by electrical stimulation. Measurement of the oxygen consumption required data on the oxygen content of the metabolism chamber at the beginning and end of stimulation. These were calculated from information on the fractional concentrations of $\mathrm{O}_{2}$ in chamber air; the animal's volume; and chamber volume, pressure, and humidity. The concentrations of $\mathrm{O}_{2}$ were determined by use of the oxygen analyzer. Humidity was measured with a Hygrodynamics humidity sensor. The initial fractional concentration of $\mathrm{O}_{2}$ was determined with the metabolism system in its open circuit configuration.

Following this, the metabolism chamber was sealed and removed from the temperature cabinet. Then the animal was immediately subjected to electrical stimulation for $2.0 \mathrm{~min}$ (2-10 volts DC shocks of variable duration) with a Grass Stimulator (model $\mathrm{S4}$ c). Chamber temperature over this period remained essen- 
tially at the level maintained in the temperature cabinet. During stimulation, the excurrent air port of the chamber was connected to a sampling balloon through a Varistaltic pump (Manostat Corp., New York). The balloon and all air lines external to the chamber were evacuated with a vacuum pump. At the end of the 2-min stimulation period, air was pumped from the chamber into the balloon for 10 sec. Approximately $500 \mathrm{~cm}^{3}$ of air was collected in this period; the condom within the chamber inflated and prevented the establishment of a large pressure deficit. The air sample in the balloon was metered via a small tube of Drierite through the paramagnetic oxygen analyzer at $150 \mathrm{~cm}^{3} / \mathrm{min}$. The oxygen concentration within the closed chamber never fell below $20.6 \%$. All gas volumes specified in connection with standard and active rates of metabolism have been corrected to STPD.

Following completion of stimulation and collection of the post-activity air sample, the lizard was immediately removed from the chamber, decapitated, and homogenized for $1 \mathrm{~min}$ in four-times its weight of $0.6 \mathrm{~N}$ perchloric acid. Homogenization involved use of an Osterizer set at maximum speed. Lactate formed during activity was measured by the method of Bennett and Licht (1972). Lactate determinations were also made on unstimulated animals at each test temperature to determine levels for resting lizards. Total lactate production during activity was obtained by subtracting the mean resting value from the total lactate concentration after activity.

\section{Results}

During stimulation Dipsosaurus underwent a period of vigorous activity generally lasting from 1 to $2 \mathrm{~min}$ at body temperature of $40^{\circ} \mathrm{C}$ or below. Activity at $45^{\circ} \mathrm{C}$ was rarely sustained for longer than one min, although the stimulation applied was identical to that at lower body temperatures. During the active period, no increase in ventilation was obvious, but upon cessation of activity, the Dipsosaurus initiated a profound hyperventilation in which tidal volume was greatly increased (see Fig. 1). This hyperventilation would serve to increase oxygen uptake and eliminate the carbon dioxide appearing as a result of both aerobic and anaerobic metabolism (the latter causes release of $\mathrm{CO}_{2}$ through the bicarbonate buffer system).

Standard and active levels of oxygen consumption at various temperatures are illustrated in Fig. 2. The standard rate generally rose with increased body temperature, but no significant increment $(p=0.23)$ occurred between $35^{\circ}$ and $40^{\circ} \mathrm{C}$. A greatly increased water loss at $45^{\circ} \mathrm{C}$ (manifested by markedly higher chamber humidities) indicated that the animals were panting and hence were no longer in a strictly resting condition. Active oxygen consumption rose with increasing temperature up to $40^{\circ} \mathrm{C}$ and was lower at $45^{\circ} \mathrm{C}$. Values of $Q_{10}$ for active and standard metabolism are summarized in Table 1 . The metabolic increment, or aerobic scope, associated with activity increased from 10 -fold to 17 -fold of standard levels of oxygen consumption between $25^{\circ}$ and $40^{\circ} \mathrm{C}$ and decreased to 7 -fold at $45^{\circ} \mathrm{C}$. Maximum aerobic scope occurred at $40^{\circ} \mathrm{C}$ and amounted to $2.27 \mathrm{~cm}^{3} \mathrm{O}_{2} /(\mathrm{g} \times \mathrm{hr})$. 


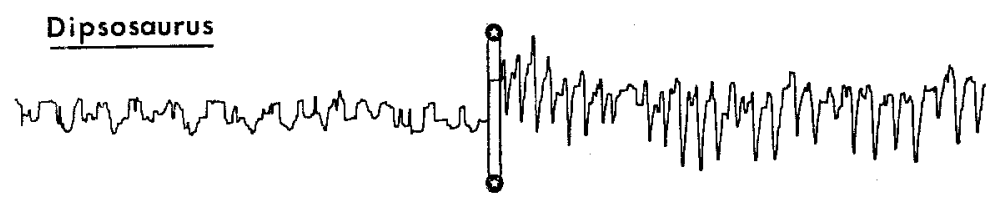

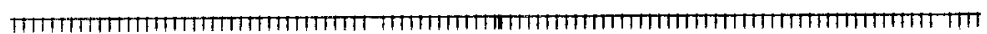

Fig. 1. Impedance pneumograph record of breathing movements in a Dipsosaurus dorsalis at rest and immediately following a 2 -min period of electrical stimulation at $27^{\circ} \mathrm{C}$. The resting and post-activity phases lie to the left and right, respectively, of the vertical bars bounded by stars. These lines mark the point on the record when the Physiograph recording oscillograph (Narco Bio-systems, Inc., Houston, Texas) was stopped (during the stimulation) and then started. The impedance pneumograph was connected to the lizard by two, 40 ga. constantan wires attached to the sides of the thorax. The hyperventilation (involving both increased frequency and amplitude of breathing movements) continued for $24 \mathrm{~min}$ following the bout of activity produced by the stimulation. The time base for the record is indicated on the lower trace, with the interval between the time marks in the lefthand third of the record representing 1 sec

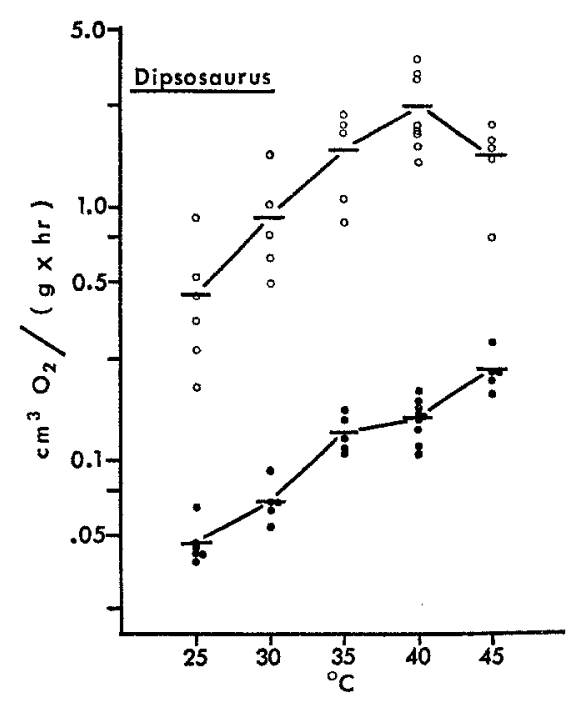

Fig. 2. The relation of oxygen consumption by Dipsosaurus dorsalis to temperature in animals under standard conditions and during maximal activity produced by 2-min of electrical stimulation (see text). Shaded circles represent standard values and unshaded circles, active ones. Short horizontal lines indicate mean values.

Data are plotted on a semilogarithmic grid 
Table 1. Values of $\mathrm{Q}_{10}$ for oxygen consumption of Dipsosaurus dorsalis

\begin{tabular}{lllll}
\hline & \multicolumn{5}{c}{ Temperature interval } \\
\cline { 2 - 5 } & $25-30^{\circ} \mathrm{C}$ & $30-35^{\circ} \mathrm{C}$ & $35-40^{\circ} \mathrm{C}$ & $40-45^{\circ} \mathrm{C}$ \\
\hline $\mathrm{Q}_{10}$ for standard rate & 2.12 & 3.48 & $1.29 \mathrm{a}$ & 2.42 \\
$\mathrm{Q}_{10}$ for active rate & 4.04 & 3.39 & 2.16 & 0.42 \\
\hline
\end{tabular}

a Not significantly different from $1.0(p>0.1)$, indicating no thermal dependence of oxygen consumption over this temperature interval.

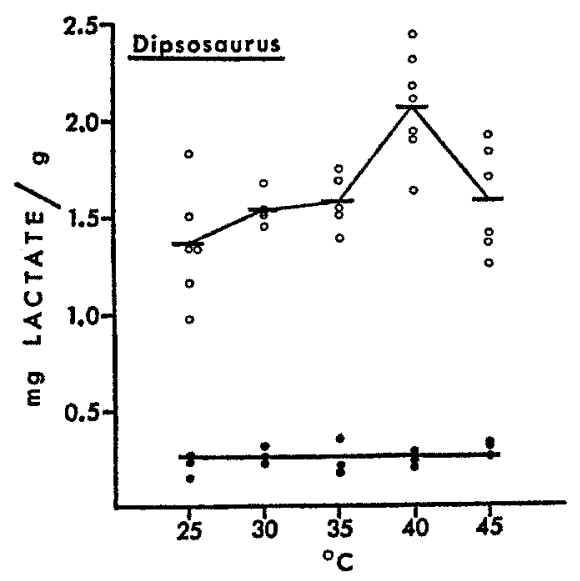

Fig. 3. The relation of total lactate concentration to temperature in Dipsosaurus dorsalis at the conclusion of a 2-min period of electrical stimulation. The short horizontal lines indicate mean values at the various temperatures. The shaded circles and long horizontal line refer to total lactate concentrations observed in resting animals

Resting and immediately post-active lactate concentrations are reported in Fig. 3. Resting lactate concentrations do not show a significant thermal dependence $(p=0.20)$. Therefore, they have been pooled, yielding a mean value of $0.25 \mathrm{mg}$ lactate $/ \mathrm{g}$ body weight. The postactivity lactate contents at $25^{\circ}, 30^{\circ}, 35^{\circ}$, and $45^{\circ} \mathrm{C}$ all approximated $1.5 \mathrm{mg} / \mathrm{g}$. However, that at $40^{\circ} \mathrm{C}$ was $2.07 \mathrm{mg} / \mathrm{g}$, significantly higher $(p<0.01)$ than at these other temperatures. Total lactate production associated with the bouts of activity ranged from $1.11 \mathrm{mg} / \mathrm{g}$ at $25^{\circ} \mathrm{C}$ to $1.82 \mathrm{mg} / \mathrm{g}$ at $40^{\circ} \mathrm{C}$.

\section{Discussion}

The standard metabolic rates measured in this study are about half those reported for Dipsosaurus of unspecified size by Cook (1949) and 
about three-fourths of the rates obtained during the day for larger animals by Dawson and Bartholomew (1958). These differences probably result from circadian metabolic fluctuations, which can produce decrements as great as $50 \%$ in lizards (Roberts, 1968; Bennett, unpublished data). The low thermal dependence of resting metabolism of Dipsosaurus from $35-40^{\circ} \mathrm{C}$ (Fig. 2) is also evident in Dawson and Bartholomew's (1958) data for this lizard. Similar plateaus have been reported for other species as well (see Cook, 1949; Dawson and Bartholomew, 1956; Dawson and Templeton, 1963; Mayhew, $1965 \mathrm{~b}$; Bennett, $1972 \mathrm{~b}$ ). These plateaus do not appear to be artifacts associated with activity, but rather seem to represent zones of metabolic stability. DeWitt (1963) has reported that Dipsosaurus have body temperatures of $38-40^{\circ} \mathrm{C}$ even at night in their burrows during summer. The fact that these temperatures lie within the range in which standard metabolism is relatively stable may indicate an adjustment leading to greater homeostasis in this poikilotherm.

The weight-specific aerobic scope of Dipsosaurus dorsalis is more than double that reported for larger reptiles (Wilson, 1971; Bennett and Dawson, MS). 'This differential is probably not indicative of singular powers of aerobiosis by our experimental subject, but rather a reflection of its relatively small body size. Weight-specific active metabolic rates have the same general size dependence as do weight=specific resting rates-smaller animals in both cases being able to attain higher rates of oxygen consumption per $\mathrm{g}$ body weight than larger animals (Hemmingsen, 1960). The aerobic scope observed in Dipsosaurus is approached by that noted in Cnemidophorus tigris of similar size, $1.75 \mathrm{~cm}^{3} \mathrm{O}_{2} /(\mathrm{g} \times \mathrm{hr})$ at $40^{\circ} \mathrm{C}$ (Asplund, 1970). Maximum aerobic scope occurs close to $40^{\circ} \mathrm{C}$ in Dipsosaurus, near the normal activity temperature of these animals. A similar situation has been found for most other reptiles examined (Wilson, 1971; Bennett and Dawson, MS).

Lactate concentrations in Dipsosaurus following activity at $25^{\circ}, 30^{\circ}$, $35^{\circ}$, and $45^{\circ} \mathrm{C}$ are similar to those reported for other species of lizards, independent of body temperature (Bennett and Licht, 1972). Lactate levels in these relatively small lizards tend to increase to $1.4-1.5 \mathrm{mg} / \mathrm{g}$ body weight with exertion. Attainment of these concentrations is accompanied by greatly decreased activity or total exhaustion. The interrelations between these factors are at present unclear. It is known that high levels of lactate production can have disruptive effects on blood $\mathrm{pH}$ and oxygen transport in lizards (Bennett, 1971) and that considerable increase occurs in blood lactate concentrations during activity (Bennett and Licht, 1972). The decreased activity or exhaustion associated with lactate accumulation may depend on: 1) a depletion of metabolizable substrate within the muscles; or 2) neural inhibition. 
The latter, which might prevent lactate concentrations from rising to injurious levels, could be mediated through a sensory system monitoring $\mathrm{pH}$ or $P_{\mathrm{CO}_{2}}$, either peripherally or within the central nervous system. The basis of the reduction in activity cannot be clarified without more detailed experiments. However, the first hypothesis would require the availability of a greater amount of substrate at $40^{\circ} \mathrm{C}$, in view of the relatively greater lactate production at that temperature than at other temperatures.

The levels of lactate production sustained at $40^{\circ} \mathrm{C}$ by Dipsosaurus are greater than any reported previously for other species of lizards. Bennett and Licht (1972) reported a value of $1.75 \mathrm{mg}$ lactate/g at $37^{\circ} \mathrm{C}$ after $90 \mathrm{sec}$ of activity, a value almost identical to that interpolated from our data. In Anolis carolinensis, Lygosoma laterale, Uta stansburiana, and Xantusia virgilis, the total lactate production at preferred thermal levels is not significantly greater than at other body temperatures (Bennett and Licht, 1972). Consequently, on the basis of present information, Dipsosaurus appears exceptional among lizards in its powers of anaerobiosis. It is able to mobilize a greater amount of energy anaerobically than other species and to produce and tolerate more lactate at normal activity temperatures than at other body temperatures.

Presumably, all the significant energy-yielding processes during physical exertion by Dipsosaurus involve oxygen consumption or lactate production. The resulting generation of ATP can be estimated from the following relations:

$1.0 \mathrm{mg}$ lactate formed $=0.0167$ mmoles ATP; $1.0 \mathrm{~cm}^{3} \mathrm{O}_{2}$ (STPD) consumed $=0.290$ mmoles ATP.

The former relation depends on the assumption that glycogen is the substrate catabolized. The latter requires a $\mathrm{P} / \mathrm{O}$ ratio of 3.0. Validation of these specifications is provided in the studies of reptilian metabolism by Privitera and Mersmann (1966) and Moberly (1968a). The ATP production estimated for Dipsosaurus from the net amount of lactate produced and of oxygen consumed during 2-min stimulation periods is plotted as a function of temperature in Fig. 4. Anaerobic processes account for a minimum of $58 \%$ and a maximum of $83 \%$ of the total energy expended, with these extremes occurring at $40^{\circ}$ and $25^{\circ} \mathrm{C}$, respectively. These figures represent conservative estimates of the role of anaerobiosis in support of activity in Dipsosaurus, since a portion of the oxygen consumption measured represents repayment of oxygen debt.

It is of considerable interest that total energy expenditure during enforced activity by Dipsosaurus reaches a maximum at $40^{\circ} \mathrm{C}$, within 


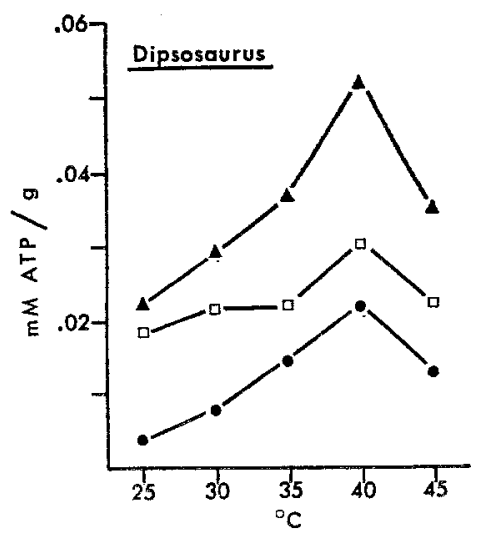

Fig. 4. Estimated weight-specific production of ATP (in mmoles/g of body weight) by Dipsosaurus dorsalis in the maximal activity produced by $2-\mathrm{min}$ of electrical stimulation at various temperatures. Circles: ATP resulting from aerobic metabolism. Squares: ATP resulting from anaerobic metabolism. Triangles: total ATP from both anaerobic and aerobic metabolism. Estimates are based on data from

Figs. 2 and 3 and relations specified in text

the normal range of body temperatures noted for this lizard during activity in nature. Surprisingly few laboratory-determined physiological variables have been found to correspond to preferred body temperature in reptiles. Heart rate increment (the difference between resting and active heart rate) (Licht, 1965), ability to produce a hypoosmotic urine (Shoemaker et al., 1967), maximal sustainable walking speed and capacity for clearance of blood lactate after activity (Moberly, 1968a, b) and aerobic metabolic scope (Wilson, 1971; Bennett and Dawson, MS) are the only notable factors. Most of these correlated variables involve energy processing during activity. It is possible that the principal physiological adaptations of reptiles to preferred thermal levels have involved capacities for rapid energy during and rapid recovery after activity.

This study was supported in part by a Miller Postdoctoral Research Fellowship to AFB and by National Science Foundation Grant GB-25022 to WRD. We thank Dr. Lon McClanahan for assistance in collecting the animals.

\section{References}

Asplund, K. K. : Metabolic scope and body temperatures of whiptail lizards (Cnemidophorus). Herpetologica 26, 403-411 (1970).

Beckman, W. A., Mitchell, J.W., Porter, W. P.: Thermal model for prediction of a desert iguana's daily and seasonal behavior. Amer. Soc. Mech. Engineers Publ. 71-WA/HT-35, 7 (1971). 
Belkin, D. A.: The running speeds of the lizards Dipsosaurus dorsalis and Callisaurus draconoides. Copeia 1961, 223-224. (1961).

Bennett, A. F.: Oxygen transport and energy metabolism in two species of lizards, Sauromalus hispidus and Varanus gouldii. Ph. D. Thesis. Ann Arbor: Univ. of Michigan 1971.

Bennett, A. F.: A comparison of activities of metabolio enzymes in lizards and rats. Comp. Biochem. Physiol. 42 B, 637-647 (1972a).

Bennett, A. F.: The effect of activity on oxygen consumption, oxygen debt, and heart rate in the lizards Varanus gouldii and Sauromalus hispidus. J. comp. Physiol. 79, 259-280 (1972 b).

Bennett, A. F., Dawson, W. R.: Reptilian metabolism. In: Biology of the Reptilia. Physiology A, vol. 5, ed. C. Gans. New York: Academic Press (in press).

Bennett, A. F., Licht, P.: Anaerobic metabolism during activity in lizards. J. comp. Physiol. 81, 277-288 (1972).

Cook, S. F.: Respiratory metabolism of certain reptiles and amphibia. Univ. Calif. Publ. Zool. 53, 367-376 (1949).

Dawson, W. R., Bartholomew, G. A.: Relation of oxygen consumption to body weight, temperature, and temperature acclimation in lizards Uta stansburiana and Sceloporus occidentalis. Physiol. Zool. 29, 40-51 (1956).

Dawson, W. R., Bartholomew, G. A.: Metabolic and eardiac responses to temperature in the lizard Dipsosaurus dorsalis. Physiol. Zool. 31, 100-111 (1958).

Dawson, W. R., Poulson, T. L.: Oxygen capacity of lizard bloods. Amer. Midl. Nat. 68, 154-164 (1962).

Dawson, W. R., Templeton, J. R.: Physiological responses to temperature in the lizard Crotaphytus collaris. Physiol. Zool. 36, 219-236 (1963).

DeWitt, C. B.: Behavioral thermoregulation in the iguanid lizard, Dipsosaurus dorsalis. Ph. D. Thesis. Ann Arbor: Univ. of Michigan 1963.

DeWitt, C. B.: Precision of thermoregulation and its relation to environmental factors in the desert iguana, Dipsosaurus dorsalis. Physiol. Zool. 40, 49-66 (1967a).

DeWitt, C. B.: Behavioral thermoregulation in the desert iguana. Science 158, 809-810 (1967b).

Dill, D. B.: Life, heat, and altitude. Physiological effects of hot climates and great heights. Cambridge: Harvard Univ. Press 1938.

Dill, D. B., Edwards, H. T., Bock, A. V., Talbott, J. H.: Properties of reptilian blood. III. The chuckwalla (Sauromalus obesus Baird). J. cell. comp. Physiol. $6,37-42(1935)$.

Fry, F. E. J.: Effects of the environment on animal activity. Pub. Ont. Fish. Res. Lab. No 68, 1-62 (1947).

Hemmingsen, A. M.: Energy metabolism as related to body size and respiratory surfaces, and its evolution. Rep. Steno Mem. Hosp. Nord. Insulinlab. 9, 1-110 $(1960)$.

Hill, R. W.: Determination of oxygen consumption using the paramagnetic oxygen analyzer. J. appl. Physiol. 38, 261-263 (1972).

Licht, P.: Effects of temperature on heart rates of lizards during rest and activity. Physiol. Zool. 38, 129-137 (1965).

Mayhew, W. W.: Growth response to photoperiodic stimulation in the lizard Dipsosaurus dorsalis. Comp. Biochem. Physiol, 14, 209-216 (1965a).

Mayhew, W. W.: Hibernation in the horned lizard, Phrynosoma m'calli. Comp. Biochem. Physiol. 16, 103-119 (1965b).

Mayhew, W. W.: Biology of desert amphibians and reptiles, p. 195-356. In: Desert biology, ed. G. W. Brown, Jr. New York: Academic Press 1968. 
Mayhew, W. W.: Reproduction in the desert lizard, Dipsosaurus dorsalis. Herpetologica 27, 57-77 (1971).

Minnich, J. E.: Water and electrolyte balance of the desert iguana, Dipsosaurus dorsalis, in its natural habitat. Comp. Biochem. Physiol. 35, 921-933 (1970a).

Minnich, J. E.: Evaporative water loss from the desert iguana, Dipsosaurus dorsalis. Copeia 1970, 575-578 (1970b).

Minnich, J. E., Shoemaker, V. H.: Diet, behavior and water turnover in the desert iguana, Dipsosaurus dorsalis. Amer. Midl. Nat. 84, 496-509 (1970).

Moberly, W. R.: Hibernation in the desert iguana, Dipsosaurus dorsalis. Physiol. Zool. 36, 152-160 (1963).

Moberly, W. R.: The metabolic responses of the common iguana, Iguana iguana, to activity under restraint. Comp. Biochem. Physiol. 27, 1-20 (1968a).

Moberly, W. R.: The metabolic responses of the common iguana, Iguana iguana, to walking and diving. Comp. Biochem. Physiol. 27, 21-32 (1968b).

Norris, K. S.: The ecology of the desert iguana Dipsosaurus dorsalis. Ecology $\mathbf{3 4}$, 265-287 (1953).

Pough, F. H.: Environmental adaptations in the blood of lizards. Comp. Biochem. Physiol. 31, 885-901 (1969).

Privitera, C. A., Mersmann, H. J.: Seasonal oxidative phosphorylation by turtle heart mitochondria. Comp. Biochem. Physiol. 17, 1045-1048 (1966).

Roberts, L. A.: Oxygen consumption in the lizard Uta stansburiana. Ecology 49, 809-819 (1968).

Shoemaker, V. H., Licht, P., Dawson, W. R.: Thermal dependenee of water and electrolyte excretion in two species of lizards. Comp. Biochem. Physiol. 28, 255-262 (1967).

Weathers, W. W.: Physiological thermoregulation in the lizard Dipsosaurus dorsalis. Copeia 1970, 549-557 (1970).

Wilson, K. J.: The relationships of activity, energy, metabolism, and body temperature in four species of lizards. Ph. D. Thesis. Clayton, Victoria: Monash Univ. 1971.

Dr. Albert F. Bennett

Department of Zoology

University of California

Berkeley, California 94720, U.S.A.
Prof. William R. Dawson

Department of Zoology

The University of Michigan

Ann Arbor, Michigan 48104, U.S.A. 